\title{
Development Tortoise shell PCR Detection Kit and Evaluation Parameter of the Kit
}

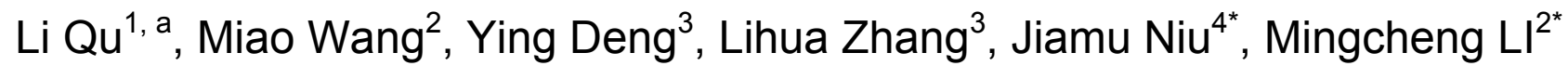 \\ ${ }^{1}$ College of Public Health, Beihua University, Jilin 132013, China \\ ${ }^{2}$ Medical College, Beihua University, Jilin 132013, China \\ ${ }^{3}$ School of Pharmacy, Beihua University, Jilin 132013, China \\ ${ }^{4}$ Scientific research department, Beihua University, Jilin 132013,China \\ aemail: chenning_qu@163.com, * Corresponding Author
}

Keywords: Tortoise shell; PCR detection Kit; Multiplex PCR

\begin{abstract}
Tortoise shell is the dry breastplate and carapace of the testudinidae animal turtle [Chinemys reevesii (Gray)]. Traditional identification methods can't meet the requirements of quality control of Tortoise shell market. We developed a detection kit for Tortoise shell DNA and to investigate the kit's index including specificity, sensitivity, repeatability and stability. The DNA detection kit was assembled by optimized salting out reagent and multiplex PCR reagent. The mtDNA of Tortoise shell was extracted by the kit, the multiplex PCR technique was carried out to authenticate samples of Tortoise shell. The value of mtDNA extracted by the kit was $1.80 \pm 0.05$. The result of multiplex PCR indicated that two distinct bands at $335 \mathrm{bp}$ and $410 \mathrm{bp}$ were shown on the agarose gel electrophoresis in genuine Tortoise shell, but there was no band in fake samples. The specificity of the kit was $100 \%$. The detection limit of the kit was $0.025 \mathrm{~g}$ of each sample. The kit was effective after being frozen-thawed for 20 times, repeatability test indicated the same result through three times. The Tortoise shell DNA detection kit has properties with high specificity, good sensitivity and stability. So it is suitable for the rapid and accurate detection of Tortoise shell.
\end{abstract}

\section{Introduction}

At present, there are more than 240 kinds of turtles animals in the world as we known. Our country existed 31 turtle, belonging to 5 families and 18 genera. Tortoise shell taste salty, bitter and slightly cold. It can kidney strong bone, nourishing blood bushing and solid after the collapse. With functions of night sweats, dizzy, bones and muscles impotent soft by more, etc[1]. Tortoise shell contains animal glue, hornof protein, fat, collagen, calcium, phosphorus, zinc, copper, strontium and other elements. So Tortoise shell is commonly used precious medicinal materials. In recent years, the market demand of tortoise shell is increased. But the tortoise record in pharmacopoeia has low reproduction rate and slowly growth speed. Lead to tortoise shell market confusion and directly affect tortoise shell safety and efficacy of the clinical application.

Mitochondrial DNA (mtDNA) is the ideal object to study the animal origin, evolution and genetic analysis as a core of genetic material. It is used as the most commonly molecular markers. "China pharmacopoeia"(2010) contains the agkistrodon and the zaocys dhumnade PCR identification method, provides a new molecular biology thought identification for traditional Chinese medicine. Our team researched tortoise shell PCR identification method since 2006, extracted the tortoise shell mtDNA, used PCR and multiplex PCR technology identified tortoiseshell successfully, developed the tortoise shell DNA testing kits on the basis and evaluated the kit. Now the report is as follows.

\section{Materials and Instrument}

\section{A Materials}

Authentic tortoise shell (labeled ZPGJ - 1, ZPGJ - 2, provided by China Offices Shall of 
Pharmaceutical and Biological Products, batch number: 121494-201102) as the kit of positive reference substance, 10 samples of tortoise shell identified by JiLin Province Food and Drug Inspection and Appraisal, the six genuine samples and the four fake samples.

\section{B Reagent}

$10 \mathrm{mmol} \cdot \mathrm{L}-1$ Tris-HCl$(\mathrm{pH}=8.0), 10 \mathrm{mmol} \cdot \mathrm{L}-1 \mathrm{Na} 2 \mathrm{EDTA}(\mathrm{pH}=8.0), 10 \%$ SDS(Beijing Dingguo biotechnology company), $50 \mathrm{mmol} \cdot \mathrm{L}-1 \mathrm{NaCl}$, Isopropyl alcohol, Proteinase $\mathrm{K}(20 \mu \mathrm{g} / \mathrm{mL}), 2 \times \mathrm{Taq}$ PCR Master Mix(Shanghai Tiangen biotech company).

\section{Instrument}

H-2050R low-temperature high-speed centrifuge (Centrifuge instrument co., LTD of Xiangyi, Changsha), PCR System 9700 gene amplification (American ABI company), DYY-8B voltage steady flow electrophoresis apparatus (Beijing Liuyi instrument factory), UV WHITE-2020D UV gel imaging analyzer (American Biorad company).

\section{Methods}

\section{A Composition of DNA kit}

Dosage of kit for 20 times detection, made up of DNA extraction and PCR amplification system. Preparation of DNA extraction reagent

With "P" means "bottle", the DNA extraction reagent made up of P1 - P6.

Preparation of PCR reaction system

Compound reaction system $(25.0 \mu \mathrm{L} / \mathrm{PCR}): 2 \mathrm{x}$ Taq PCR Master Mix 12.5 $\mu \mathrm{L}$; Cytochrome b (cyt b) upstream and downstream primers each $1 \mu \mathrm{L}$; Cytochrome $\mathrm{C}$ oxidase subunit I (CoI) upstream and downstream primers each $1 \mu \mathrm{L}$; Add sterilization double evaporate water to $23.0 \mu \mathrm{L}$; Add $2.0 \mu \mathrm{L}$ waiting for samples, positive and negative reference substance.

PCR Amplification conditions

Amplification program for $94^{\circ} \mathrm{C}$ modified $5 \mathrm{~min}$, then 30 cycle, condition of $94^{\circ} \mathrm{C}$ modified $30 \mathrm{~s}$, $61{ }^{\circ} \mathrm{C}$ annealing $30 \mathrm{~s}, 72^{\circ} \mathrm{C}$ extending $30 \mathrm{~s}$, the last extending $72^{\circ} \mathrm{C} 10 \mathrm{~min}$.

\section{$B$ The kits detect tortoise shell samples}

Extraction of DNA from tortoise shell with the Kit

Samples from $1 \mathrm{~g}$ tortoise shell tripsis to $1 \mathrm{~mm} 3$, weight $0.1 \mathrm{~g}$ samples and add P1 $500 \mu \mathrm{L}, \mathrm{P} 230 \mu \mathrm{L}$, P3 $15 \mu \mathrm{L}$ (after blending in $56^{\circ} \mathrm{C}$ water bath oscillation $16-18 \mathrm{~h}$. Remove and add $\mathrm{P} 4500 \mu \mathrm{L}$, gently oscillation $10 \mathrm{~min}, 4^{\circ} \mathrm{C} 11000 \mathrm{r} \cdot \mathrm{min}-1 \times 10 \mathrm{~min}$ centrifuge, take the supernatant and add isovolumetric $\mathrm{P} 5$, place $1 \mathrm{~h}$ at $-20^{\circ} \mathrm{C}$. Remove and centrifuge $4{ }^{\circ} \mathrm{C} 11000 \mathrm{r} \cdot \mathrm{min}-1 \times 10 \mathrm{~min}$, abandon the supernatant, add $70 \%$ alcohol $500 \mu \mathrm{L}$ to precipitate fully flush, $4^{\circ} \mathrm{C} 11000 \mathrm{r} \cdot \mathrm{min}-1 \times 10 \mathrm{~min}$ centrifuge, precipitation dry at room temperature. Add P6 $80 \mu \mathrm{L}$ dissolve DNA, as a template for PCR reaction. Measurement the Concentration and Purity of DNA Extract

Take DNA extract $3 \mu \mathrm{L}$, measured A260 and A280 with ultramicro ultraviolet spectrophotometer at $260 \mathrm{~nm}$ and $280 \mathrm{~nm}$ absorbance, calculated DNA purity and concentration determined by the ratio of $\mathrm{A} 260$ / A280.

PCR Detection

Add DNA extract, positive control and negative control liquid $2 \mu \mathrm{L}$ to the PCR reaction tube respectively. Place the centrifugal tube into PCR instrument, set the PCR reaction parameters, it should be tested within $1 \mathrm{~h}$ after PCR. Pick up amplification reaction tube liquid $15 \mu \mathrm{L} \sim 20 \mu \mathrm{L}$ point in the hole of $2 \%$ agarose gel with GelRed dye, $10 \mathrm{v} / \mathrm{cm}$ electrophoresis, put the gel at uv analyzer on observation, take pictures.

\section{Evaluation parameter of he kit}

Specificity Extraction of three authentic tortoiseshell and three falsify tortoise shell identified by JiLin Province Food and Drug Inspection and Appraisal tested by kit method respectively.

Sensibility Randomly selected one authentic tortoiseshell, set sample as 1 times the gradient decreasing to $0.003 \mathrm{~g}$, take DNA extract $2 \mu \mathrm{L}$ for PCR detection, tested by kit method respectively.

Repeatability Randomly selected two authentic tortoiseshell and one falsify tortoise shell inspection by kit method respectively under the condition of the same laboratory, by the same 
experimenter repeat 3 times.

Stability Randomly selected a kit from $-20^{\circ} \mathrm{C}$, dissolved under room temperature, then placed $-20^{\circ} \mathrm{C}$, frozen respectively after $1,5,10$ and 20 times, test DNA extraction, negetive and positive reference substance within the kit.

\section{Results}

A Detection purity and concentration of tortoise shell extract sample mtDNA by kit

Purity of the sample mtDNA was $1.80 \pm 0.05$ extracted by kit, the concentration was $1.90 \mu \mathrm{g} / \mathrm{L}$. It showed that the DNA samples have no protein and RNA pollution extracted by kit (table 1).

Tab.1 Purities and concentration of 12 Tortoise shell samples

\begin{tabular}{|c|c|c|c|c|c|c|}
\hline Number & Size (g) & Genuine or Counter fact & A260 & A280 & purity & C/ $/ \mathbf{g}^{-\mathbf{L}^{-1}}$ \\
\hline ZPGJ-1 & 5 & Genuine & 0.378 & 0.209 & 1.81 & 1.89 \\
\hline ZPGJ-2 & 5 & Genuine & 0.376 & 0.211 & 1.78 & 1.88 \\
\hline JLGJ-1 & 5 & Genuine & 0.382 & 0.215 & 1.78 & 1.91 \\
\hline JLGJ-2 & 5 & Genuine & 0.379 & 0.213 & 1.78 & 1.90 \\
\hline JLGJ-3 & 5 & Genuine & 0.380 & 0.209 & 1.82 & 1.90 \\
\hline JLGJ-4 & 5 & Genuine & 0.378 & 0.211 & 1.79 & 1.89 \\
\hline JLGJ-5 & 5 & Genuine & 0.382 & 0.213 & 1.79 & 1.91 \\
\hline JLGJ-6 & 5 & Genuine & 0.380 & 0.210 & 1.81 & 1.90 \\
\hline JLGJ-7 & 5 & Counter fact & 0.377 & 0.212 & 1.78 & 1.89 \\
\hline JLGJ-8 & 5 & Counter fact & 0.381 & 0.208 & 1.83 & 1.91 \\
\hline JLGJ-9 & 5 & Counter fact & 0.379 & 0.214 & 1.77 & 1.90 \\
\hline JLGJ-10 & 5 & Counter fact & 0.383 & 0.211 & 1.82 & 1.92 \\
\hline
\end{tabular}

\section{B Tortoiseshell mtDNA PCR products agarose gel electrophoresis}

After specific pairs of primers PCR amplification, three authentic tortoise shell mtDNA specific bind with cyt $b$ and CoI primers, amplification products appear two clear bands in $335 \mathrm{bp}$ and 410 $\mathrm{bp}$, and consistent with positive reference substance location, negative reference substance and three falsify tortoise shell without amplification band (Figure 1).

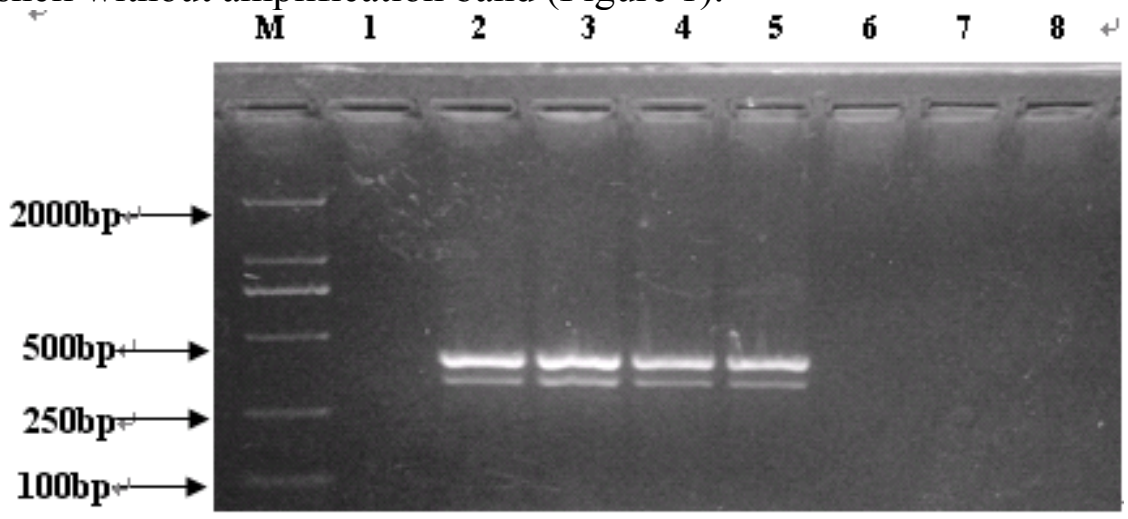

Fig.1 Agarose gel electrophoresis of the Tortoise shell sample by kit

M: DL2000 DNA Marker; 1: negative control ;2: positive control;

\section{Evaluation parameters of the kits}

$$
3: \text { JLGJ-1; 4:JLGJ-2; 5:JLGJ-3;6:JLGJ-7; }: \text { JLGJ-8; 8:JLGJ-9 }
$$

Specificity Tortoise shell samples test by kiti dentified by JiLin Province Food and Drug Inspection and Appraisal, all authentic tortoise shell appear two clear bands in $335 \mathrm{bp}$ and $410 \mathrm{bp}$, and consistent with the positive control, and all falsify tortoise shell and negative control don't appear band, kit appraisal results and JiLin Province Food and Drug Inspection and Appraisal method identification results are identical, kit specificity is $100 \%$ (Figure 1).

Sensibility The results showed that tortoise shell sample is $0.025 \mathrm{~g}$ still can amplify the target two 
bands in $335 \mathrm{bp}$ and 410 bp by the method of kit (Figure 2).

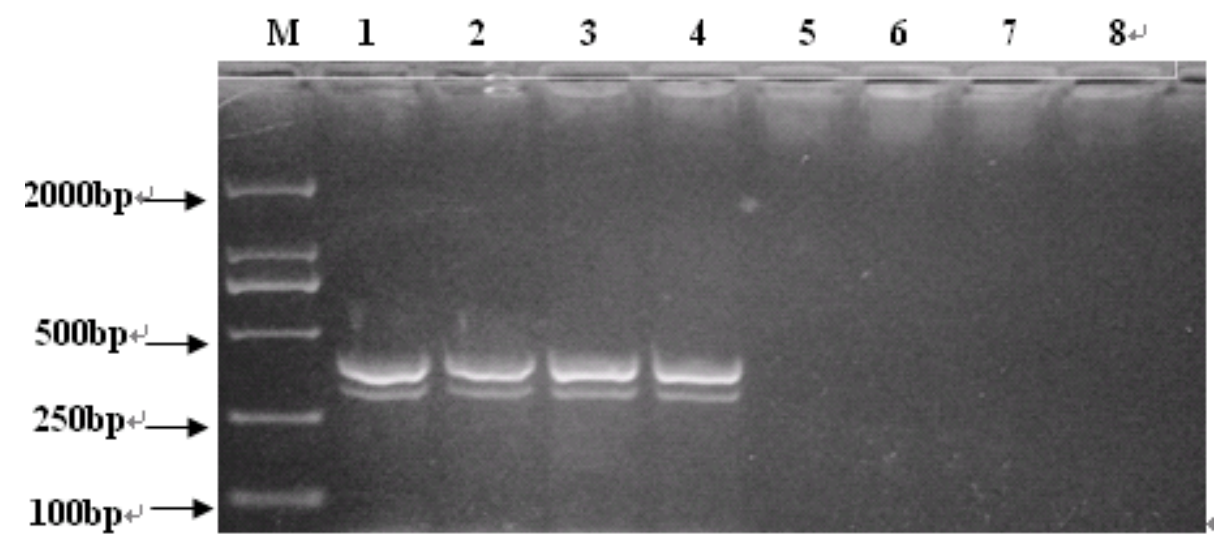

Fig. 2 Agarose gel electrophoresis of the Tortoise shell in the kit assay sensibility M:DL2000 DNA Marker; 1: positive control; 2-7: weight of the Tortoise shell samples is $0.1 \mathrm{~g}-0.003 \mathrm{~g} ; 8$ : negative control

Repeatability Two authentic tortoise shell and one falsify tortoise shell tested 3 times repeatly, authentic tortoise shell appear two clear bands in $335 \mathrm{bp}$ and $410 \mathrm{bp}$, and consistent with the positive control, and falsify tortoise shell and negative control don't appear band, explaining kit has good repeatability(Figure omit).

Stability Kit dealt with 1, 5, 10, 20 times respectively by repeated freezing and thawing can still extract tortoise shell DNA and amplify the target bands in $335 \mathrm{bp}$ and $410 \mathrm{bp}$, show that kit has a good stability (Figure 3).

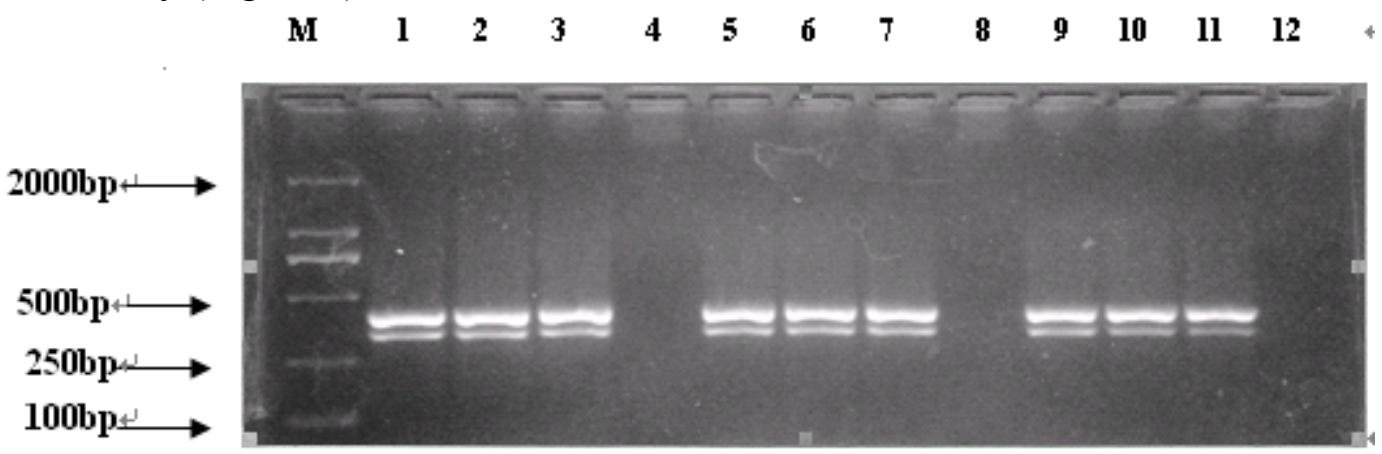

Fig. 3 Agarose gel electrophoresis of the Tortoise shell in the kit assay stability

M: DL2000 DNA Marker;1、5、9-the result of testing positive control after frozen-thawed of the kit for 5、10、20 times respectively; 4、8、12- the result of testing negative control after frozen-thawed of the kit for 5、10、20 times respectively; $2 、 6 、 10$ - indicated the result of testing JLGJ-4 by kit after frozen-thawed of the kit for 5、10、20 times respectively;3、7、11- indicated the result of testing JLGJ-5 by kit after frozen-thawed of the kit for 5、10、20 times respectively

\section{Discussion}

Traditional Chinese medicine of tortoise shell quality evaluation method is mainly appearance, microstructure and physical and chemical identification, etc. Traditional appearance identification is the main basis of breastplate and carapace properties such as shape, color, smell and texture characteristics [2], the method is simple, quick, but the lack of clear boundaries. Microscopic identification method is the magnification characteristic of tortoise shell texture and plaques, applicable to the broken appearance of tortoise shell, but this method standard has not yet mature. Physical and chemical identification of tortoise shell is analysis it's containing in the main chemical composition or the characteristic components through physical or chemical methods, in order to achieve the purpose of its authenticity identification [3], but tortoise is very similar to the chemical composition, so it brought difficulties for the physical and chemical identification of tortoise shell. 
Tortoise shell dentification method in China pharmacopoeia(2010) is thin layer chromatography (TLC). TLC method can contain multiple samples and more information in a chromatography plate, it has the dual role of isolation and identification. Hanying $\mathrm{Gu}[4]$ identified Ann cloth armor, red mud ear tortoise shell, the Burmese tortoise shell, the flower tortoise shell and authentic tortoise shell using TLC, chromatogram shows that five kinds of tortoise shell contains the free amino acids composition is very similar, it is difficult to distinguish between significantly. Thus, although TLC method can effectively analysis, identify relevant component of tortoise shell, but can't infer that tortoise shell source of species.

Tortoise shell species differences in the traceability is genotype differences, namely differences in DNA sequence. Therefore, to identify tortoise shell by comparing the difference between the different species tortoiseshell gene sequences become a reliable new method. At present, the DNA molecular diagnostic techniques used in traditional Chinese medicine identification has achieved great development[5,6]. "China pharmacopoeia"(2010) contains the agkistrodon and the zaocys dhumnade PCR identification method[7], based on the above technical support, our team develop tortoiseshell DNA testing kits, including two system of DNA extraction and PCR amplification, can identify different species of tortoise shell one step.

We found that different manufacturers, different batches reagent can affect the result of the extraction of tortoise shell DNA after repeated experiments, thus, the DNA extraction kit unify reagent, avoiding the different sources, different batches of the unknown impact of factors on the experiment. In addition, the kit step is simple to extract the tortoise shell mtDNA, the DNA extraction process can be completed in $2 \mathrm{~h}$ remove water bath time, shortens the appraisal cycle. Finally, DNA purity can reach $1.80 \pm 0.05$ by kit, shows that this method to extract DNA was of high purity, is advantageous to the subsequent experiments.

Multiplex PCR technology is used in kit, pairs of specific primers design to aim at Cytb and COI gene of the mtDNA, has higher specificity, can successful identify the tortoise shell included in pharmacopoeia and other species of tortoise shell[8]. Annealing temperature determine success or failure of experiment by pairs of primers for PCR amplification, choose temperature at $61^{\circ} \mathrm{C}$ after repeated experiments, authentic tortoiseshell appear two clear bands in $335 \mathrm{bp}$ and $410 \mathrm{bp}$ at this annealing temperature.

Our team can fast identify 10 kinds of Chinese medicinal materials using polymerase chain reaction. Mingcheng Li[9, 10] studied mink heart mtDNA characteristics, and established the mink heart DNA fingerprint characteristic appraisal method; Yujuan Gu[11]identified pilose antler application RAPD. Shuai Wang[12] established ginseng directly amplified fragment length polymorphism DNA fingerprint.

Tortoiseshell DNA testing kit developed by our team has the following advantages: first, the kit identification is realized by using one-step process from extraction to amplification, shorten the time, can identify a large number of samples be in a short period of time; Second, the kits parameters show that, this kit has the very good specificity, sensitivity, repeatability and stability; Third, operation can be realized the real experimental process standardization, automation, simple operation with the kit manual in strict accordance, the intuitive judgment, can effectively alleviate the lack of professional identification. Based on the above characteristics, the kit can be widely used in drug manufacturers and drug inspection agency. 


\section{Acknowledgement}

In this paper, the research was sponsored by the "Twelfth five-year" science and technology research project of jilin province department of education (Project No. 2015No.154) and the Project of health department of Jilin province (Project No. 2014Z085).

\section{References}

[1] Ch. P (2010) Vol I [S] . 2010:168.

[2]LI Y,WANG S F.True and False Identification of Tortoise shell[J].Chinese Traditional and Herbal Drug,2000,31(11):866-867.

[3]LEI J T.Study on Shape and Composition of Tortoise shell[J].JL Mil Med Coll FMMU,2005,26(1),43-44.

[4] GU Y H. Pharmacognostic Study on Tortoise shell[D]. Chengdu: Chengdu university of TCM, 2007: 1-70.

[5]Hebert PDN, Cywinska A, Ball SL. Biological identification through DNA barcodes. Pro Bio Sci, 2003, 70:313-321.

[6]TANG X J, FENG C Q, HUANG L Q. High specific PCR identification of Agkistrodon and its adulterants . Chin Pharm J Anal, 2006, 2:152-155.

[7]SONG W C, SONG S W, LIU D F. Specific PCR identification of Agkistrodon and its common adulterants . China Journal of Chinese Materia Medic, 2007, 12:1220-1222.

[8]Castresana J. Cytochrome b phylogeny and the taxonomy of great apes and mammals. Mol Biol Evol, 2001, 18:465-471.

[9] ZHANG L H, LI M C, WANG B M, et al. Identification and characterization of mitochondrial DNA in Martes zibellina L. heart [J] . Chin Pharm J, 2008, 43(22): 1694-1696.

[10] LI M, XIA W, WANG M, et al. Application of molecular genetics method for differentiating Martes zibellina L. heart from its adult erants in traditional Chinese medicine based on mitochondrial cytochrome b gene [J] . Mitochondrial DNA,2014,25(1):78-82.

[11] GU Y J, ZHANG L H, Fu G L. Mitochondrial DNA fingerprint identification of Velvet antler [J] . Chin Pharm J , 2013, 03: 170-173.

[12] WANG S, WANG H, ZHANG L H, et al. Identification of Panax ginsheng C. A. Meyer Cv. Silvatica and Cultivated Panax ginseng by DALP Fingerprint $[\mathrm{J}]$. Chin Pharm J , 2013, 09: 677-680. 